\title{
Doña Bárbara y lo político
}

\section{Doña Bárbara and the political}

\author{
Ioannis Antzus Ramos*
}

Resumen: En este artículo se propone una interpretación de la novela Doña Bárbara (1929) de Rómulo Gallegos a partir de la dialéctica entre la totalidad y el exceso que ella pone en juego. Su discurso novelesco plantea la creación de un orden social armónico y bien compensado, sin embargo, este orden sólo se consigue al precio de excluir aquello que lo está suplementando. El hallazgo es que el conflicto político entre el consenso deseado y aquello que lo excede, pero que ayuda a fundarlo, se aprecia en la concepción estética y lingǘstica de esta novela.

PalaBras clave: Doña Bárbara, Rómulo Gallegos, Novela venezolana, Literatura venezolana.

ABSTRACT: This article offers an interpretation of Rómulo Gallegos' Doña Bárbara (1929) based in the dialectics between totality and excess displayed in it. The novel proposes the foundation of a harmonic and well balanced social order. Nevertheless, this order is achieved only at the cost of excluding the one thing that supplements it. The conclusion is that the political conflict between the desired consensus and that that exceeds it, but provides it with proper grounding, is found in the linguistic as well as the aesthetic conception of the novel.

Key woros: Doña Bárbara, Rómulo Gallegos, Venezuelan Novel, Venezuelan Literature.

Recibido: 4 de octubre de 2017

Aceptado: 17 de enero de 2018

American University in Dubai (yananra@hotmail.com). 
...lo que se requiere es un trabajo de canalización. Hoy corren desbordadas estas fuerzas del instinto como ríos salidos de madre o, mejor dicho, como torrentes nuevos que aún no bubieran abondado con su propia fuerza el cauce refrenador de su curso, pero mañana, cuando les hayamos construido canales

regulares se deslizarán por ellos aguas claras y sosegadas, a cuyas orillas se pueden plantar sin peligro vallas y plantíos.

Rómulo Gallegos, "Necesidad de valores culturales". El Cojo Ilustrado, 1912

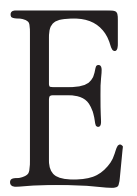

$\mathrm{n}$ un artículo escrito con motivo de los ochenta años de la publicación de Doña Bárbara (1929), el crítico Javier Lasarte recordaba un texto suyo titulado "Lecturas en pugna", de 2004, en el que planteaba que la crítica había interpretado esta novela de dos maneras opuestas. En aquel artículo, Lasarte "intentaba mostrar el grado de 'maltrato' que algunos críticos, como Gerald Martin o Doris Sommer, habían infringido a la novela, al adscribirla genealógicamente al paradigma-Sarmiento y su tesis sobre civilización vs barbarie" y prefería plegarse, en cambio, "a lecturas que, con menor fortuna, prefirieron desestimar la vinculación con Sarmiento y marcar la conciliación de ambos mundos enfrentados como norte de la novela" (Lasarte 2011: 42). ${ }^{1}$ De este modo, Lasarte rechazaba concebir la obra de Gallegos como "una nueva estrategia de liberalismo decimonónico", y prefería vincularla en cambio a la "defensa narrativa [...] de un mestizaje populista de corte martiano" y "a la idea de pacto social y cultural" (42-44).

Desde nuestra perspectiva, la distinción que establece Lasarte en las interpretaciones de Doña Bárbara no tendría tanto que ver con errores de la crítica o con una supuesta voluntad de ciertos exégetas de "maltratar" o de "juzgar" la novela, sino que esta ambigüedad formaría parte de la propia

1 Según Javier Lasarte, también Mariano Picón Salas, Juan Liscano y Nelson Osorio compartirían esta misma interpretación de la obra. Curiosamente, todos los críticos que menciona como defensores de esta postura o son venezolanos o residieron durante largas temporadas en Venezuela. 
obra. Si bien la novela admite ambas lecturas, lo que está en juego en la crítica de Lasarte es una voluntad política de privilegiar una interpretación sobre la otra. En efecto, descartar la vinculación con el "paradigma-Sarmiento" supone rechazar la dimensión de antagonismo que está implícita en la novela y por lo tanto la manera en que lo político se manifiesta en ella. Defender la síntesis de los términos opuestos como única lectura posible responde, quizá, a la intención de reconstruir el mensaje que Gallegos quería promover a través de la obra. Sin embargo, el lenguaje (la novela, en este caso) es un medio imperfecto y, desgraciadamente, las palabras dicen siempre más y menos de lo que queremos que digan. Al privilegiar exclusivamente la síntesis de los términos enfrentados, Lasarte restituye lo que el autor quería transmitir al precio de restarle complejidad a la novela.

En uno de los artículos críticos fundacionales sobre esta obra, titulado "Doña Bárbara escribe la Ley del Llano" (1985), Roberto González Echevarría (2001: 71-109) planteaba precisamente que la modernidad de esta novela consistía en su capacidad para proponer una visión orgánica de lo real y cuestionarla críticamente al mismo tiempo. Y esto al menos en dos sentidos. En primer lugar, este crítico proponía que había que considerar a Doña Bárbara una novela plenamente moderna porque cuestionaba el mito de legitimidad de la literatura latinoamericana, es decir, la supuesta coherencia entre la obra y la vida, y entre el lenguaje y el mundo. De acuerdo con González Echevarría, la voz narrativa quiere que Doña Bárbara sea leída como una pugna alegórica entre la civilización y la barbarie, y reclama permanentemente la pertinencia de esta interpretación, que supone una relación unívoca entre el significante y el significado. El crítico cubano establece, sin embargo, que el propio recurso a la alegoría "consiste en decir o interpretar más de lo que se quiere o se ha querido decir, es un suplemento de significación que escapa más allá de las intenciones y reglas impuestas por el texto mismo" (91). Por lo tanto, desde su óptica, es preciso leer la obra más allá del código de lectura que ella misma propone y revelar aquello que la alegoría está suplementando.

En segundo lugar, y en relación con lo anterior, González Echevarría analiza la concepción de la ley y de la escritura que aparece en la 
novela, e indica que ninguna de las dos puede remitir a su origen, ya que éste depende de una violencia inicial que funciona como un exceso o una negatividad. Al respecto señala: "en el caso de la pesquisa de Santos, sabemos que el origen de la escritura es impuro, que la violencia inicial de Evaristo es lo que ha marcado la tierra y la ha hecho propiedad suya y de sus descendientes. Entre esa violencia inicial y la empresa de Santos no hay posible acople" (94). Así, el crítico concluye que "la interacción entre la vastedad del llano y los esfuerzos por ponerle límites [... produce en el lector un efecto desestabilizador que borra o cancela constantemente no sólo la autoridad del texto, sino también la lectura doctrinaria que la alegoría, en un nivel primario sugiere" (95). Lo que indica González Echevarría, en suma, es que tanto la ley como la escritura dependen de un suplemento (la violencia), que les da origen y que invalida la intención alegórica (oposición civilización-barbarie) que el texto sugiere en un nivel más superficial. Por eso él propone la necesidad de ir más allá de la interpretación literal que la novela establece sobre sí misma para entender bien la concepción de la ley y de la escritura que ella pone en juego.

A continuación, trataremos de profundizar en las interpretaciones de Javier Lasarte y de Roberto González Echevarría, atendiendo sobre todo a la cuestión de "lo político" en Doña Bárbara. Se abordará este elemento en un doble sentido: siguiendo la línea abierta por González Echevarría, analizaremos el exceso que funda lo político en la novela; al hacerlo, ahondaremos en la condición de posibilidad del proyecto doctrinal de Doña Bárbara y pondremos en cuestión lecturas como las de Javier Lasarte, que, al no considerar esta dimensión suplementaria, se han limitado a reconstruir el mensaje más visible de la novela.

Si bien es evidente que la preocupación por la ley y por la escritura ocupa un lugar fundamental en Doña Bárbara, no hay que perder la perspectiva de que el objetivo principal de la obra es plantear alegóricamente un proyecto nacional para Venezuela. Afirmar esto equivale a reconocer que esta novela tiene un carácter esencialmente político, y este aspecto es algo en lo que la mayor parte de la crítica parece estar de acuerdo. Emir Rodríguez Monegal, por ejemplo, señaló que Doña Bárbara es "uno de 
los libros fundacionales de nuestras letras: un libro-nación" (1991: 119), y Doris Sommer afirmó que esta obra "se ha convertido en la novela nacional de Venezuela; con la ventaja de no tener que competir por tal honor con libros del siglo XIX" (2004: 350). La propia Sommer llamaba a Gallegos "escritor-estadista" y señalaba que "por medio de Doña Bárbara, el presidente Gallegos había sido un gran divulgador de los programas populistas en Venezuela" (2004: 350). Igualmente, Javier Lasarte, en el artículo que hemos citado al comienzo, indicaba que en esta novela se aprecia "la voluntad de 'hacer cosas' con el pueblo y la nación" y añadía que ella "desvela la posibilidad $[\ldots]$ de una nueva política: la del nacionalismo populista" (43).

A pesar de reconocer la dimensión fundacional y políica de Doña Bárbara, lo cierto es que la crítica no ha analizado en toda su extensión de qué manera esta dimensión se manifiesta en la novela. En las pocas ocasiones en que los críticos han tratado de responder a esta interrogante, las soluciones ofrecidas han sido insuficientes. Así, Javier Lasarte se preguntaba por la manera en que la novela construye el pacto "populista modernizador y democratizador, unificador y pacificador" y respondía simplemente que "Gallegos en Doña Bárbara hará de la palabra, recta o amorosa, pero siempre educativa, el instrumento de la nueva política" (48). Doris Sommer, por su parte, profundizaba un poco más al indicar que "leer Doña Bárba$r a$ como un romance nacional es leer una serie de suturas defensivamente populistas donde todos los cabos sueltos [...] son atados con ansiedad y donde cualquier contaminación entre categorías como masculino y femenino es considerada como una hemorragia" (350). Con todo, tampoco esta crítica se adentraba en la novela para mostrar explícitamente cuáles eran los "cabos sueltos" que debían ser atados y en función de qué objetivo. Sin descartar estas valiosas aportaciones, pero con el ánimo de ofrecer una interpretación original de la novela, nuestra intención aquí será analizar expresamente en qué consiste lo político en Doña Bárbara. Si la crítica está en lo cierto y la novela ha contribuido a fundar simbólicamente la Venezuela del siglo XX, resulta imprescindible entender con precisión los procesos a partir de los cuales se produce en la obra esta fundación. 
Doña Bárbara pone en juego, y esto constituye lo fundamental de su mensaje, un enfrentamiento entre dos lógicas sociales antagónicas, es decir, entre dos hegemonías. En este sentido se ocupa de "lo político", que, como ha indicado Chantal Mouffe, "tiene que ver con el modo mismo en que se instituye la sociedad", lo cual supone "la formación de un 'nosotros' como opuesto a un 'ellos"' y conlleva siempre una dimensión de conflicto y de antagonismo (2011: 15-25). Ahora bien, para determinar la dimensión de "lo político" en Doña Bárbara es fundamental localizar el verdadero antagonismo que tiene lugar en la obra. En términos generales, se puede afirmar que la novela muestra una pugna entre la civilización y la barbarie; sin embargo, para entender bien el conflicto que se da en su interior es preciso no esencializar estas categorías e interpretarlas a partir de lo que plantea el propio texto. En efecto, como ha indicado la propia Chantal Mouffe,

[...] nunca nos enfrentamos a oposiciones "nosotros/ellos" que expresen identidades esencialistas preexistentes al proceso de identificación. Además, [...] el "ellos" representa la condición de posibilidad del "nosotros", su "exterioridad constitutiva". Esto significa que la constitución de un "nosotros" específico depende siempre del tipo de "ellos" del cual se diferencia. Este punto es crucial, ya que nos permite concebir la posibilidad de diferentes tipos de relación nosotros/ellos de acuerdo al modo en que el "ellos" es construido (25).

Se trata entonces de volver a la novela con cuidado y de observar específicamente quiénes y cómo representan la "civilización" - el "nosotros" respaldado por la instancia narrativa-, y quiénes y cómo personifican la "barbarie" -el "ellos" antagónico. Dicho de otra manera, hay que responder quiénes y cómo constituyen el orden social que el discurso novelesco promueve, y quiénes y cómo quedan fuera de ese consenso. Es a través de esa diferenciación que se plantea "lo político" en la novela.

Antes de la llegada de Santos Luzardo a Altamira, prevalece en ese territorio la Ley del Llano, es decir, la hegemonía definida por doña Bárbara y aceptada por sus acólitos. Esta hegemonía se basaba en una ley comple- 
tamente arbitraria, hecha a la medida de "la devoradora de hombres" e implementada a través de la violencia y del miedo:

Altamira, descuidada por su dueño, en manos de administradores fácilmente sobornables, fue la presa predilecta de su ambición de dominio [se refiere a la ambición de Doña Bárbara]. Leguas y leguas diéronle los litigios, y entre uno y otro el lindero de El Miedo iba metiéndose por tierras altamireñas, mediante una simple mudanza de los postes, favorecida por la deliberada imprecisión y oscuridad de los términos con que los jueces comprados redactaban las sentencias y por la complicidad de los mayordomos de Luzardo, que se hacían de la vista gorda (2015: 151).

En este contexto, la llegada del joven abogado pone en marcha un movimiento contrahegemónico que supone una nueva distribución de lo sensible y de los afectos, y una nueva definición del mundo común. ${ }^{2}$ En efecto, Santos Luzardo llega al Llano con "la misma tendencia de irrefrenable acometividad que causó la ruina de los Luzardos; pero con la diferencia de que él la subordinaba a un ideal: luchar con doña Bárbara, criatura y personificación de los tiempos que corrían, no sería solamente salvar Altamira, sino contribuir a la destrucción de las fuerzas retardatarias de la prosperidad del Llano" (Gallegos 2015: 140-141). La contrahegemonía representada por Santos Luzardo (que es respaldada también por la voz narrativa $)^{3}$ buscará instaurar un orden liberal basado en la defensa de la ley y de la cultura, e incluir en él a un sector del pueblo. Se aprecia así más claramente en qué consiste la noción de "civilización" que pone en juego la novela. "Civilización" es el intento de sentar las bases del liberalismo político y de sumar a ese liberalismo a los sectores populares capaces de

2 Castro-Urioste ha llamado la atención sobre el movimiento contrahegemónico que protagoniza Santos: "Inicialmente el llano se encuentra 'gobernado' bajo cierto orden y la aparición de un elemento extraño (Santos Luzardo) altera tal situación. Así, Luzardo, quien regresa al llano a iniciar su 'conquista', es el portador de la acción dramática" (1994: 135).

3 La propia novela está narrada desde una perspectiva que apoya la visión de Santos Luzardo. Como lo ha indicado Dessau, "en la obra se opta por el punto de vista que pretende que el pueblo no sea capaz de ser el protagonista de la historia y que por eso necesita una élite culta para liberarlo y dirigirlo" (1991: 134). 
aceptar el liderazgo letrado y de integrarse al orden político y social que éste promueve. En este sentido, la estrategia de Doña Bárbara se entiende mejor en el marco de las grandes transformaciones socio-políticas que estaban teniendo lugar en América Latina y, particularmente, como parte de la estrategia de los sectores medios en ascenso que querían consolidar su poder asumiendo la representatividad del pueblo. Conviene aclarar, sin embargo, que, en la novela, la noción de civilización no solo viene impuesta desde arriba - es decir, desde la visión letrada de Santos- sino que se impulsa también desde abajo, pues los sectores populares "luzarderos" reclaman también al amo una actitud firme y decidida, que le permita imponerse sobre el sector antagonista. ${ }^{4} \mathrm{~A}$ pesar de carecer de formación reglada, los peones fieles al dueño de Altamira poseen una ética esencial y armónica, y desde esa posición intervendrán en la conversión de Santos Luzardo en líder indiscutido del Llano. Así, el arraigo de lo culto en lo popular se plantea en la novela solo a partir del reconocimiento de que el pueblo leal y productivo encarna un ethos esencial que garantiza el liderazgo de las élites. Vemos así que en el pensamiento de Gallegos la civilización - o, lo que es lo mismo, el liberalismo- se corresponde con una ética natural o esencial que resulta de la armonía de los contrarios y, que, si bien encarna ejemplarmente en la figura de Santos, está también presente en el pueblo que lo respalda.

La voluntad manifiesta de Santos (y de la instancia narrativa) de encauzar a un sector del pueblo (siendo, al mismo tiempo, encauzado por él) nos lleva a plantearnos cómo aparece tematizado "lo popular" en esta novela y, con ello, qué significa verdaderamente la "barbarie". El propio Gallegos nos ofrece en la novela una definición que resulta esclarecedora. En un momento en que Santos se olvida del proyecto civilizatorio y parece

4 La influencia de los peones sobre Santos se puede advertir en el episodio de la doma en el capítulo 8 de la primera parte (Gallegos 2015: 199). Sin embargo, ellos habrían ejercido una influencia indirecta sobre él desde el momento en que, al entrar en contacto con él, no reconocen su hombría. Así, Carmelito afirma, al conocer a Santos: "iHum! - murmuró entre dientes - ¿y este es el hombre del que tanto esperábamos? Con este patiquincito presumido no se va a ninguna parte" (157). 
sucumbir a las fuerzas retrógradas del Llano, reflexiona de la siguiente manera: "Después de todo - se decía - la barbarie tiene sus encantos, es algo hermoso que vale la pena vivirlo, es la plenitud del hombre rebelde a toda limitación" (352. Subrayado nuestro). De igual manera, más adelante, la "barbarie" es explícitamente comparada con el tremedal, es decir, con ese pedazo de tierra próximo a La Chusmita que quedaba como un suplemento en el contrato inicial firmado por José Luzardo y Sebastián Barquero y que dio origen al enfrentamiento entre las familias. ${ }^{5}$ Así, en un momento de la novela en el que se habla de la decadencia de Lorenzo Barquero, se dice que Santos "también había comenzado a hundirse en aquel otro tremedal de la barbarie, que no perdona a quienes se arrojan a ella" (445-446. Subrayado nuestro). Según se aprecia en estas citas, a lo largo de toda la obra la barbarie aparece vinculada a la noción de exceso. En efecto, en la concepción de Gallegos "barbarie" es lo que no respeta el límite, es decir, cualquier sujeto o elemento que tiende a la infinitud y que transgrede o disemina la noción de frontera, sea esta física o simbólica.

Respecto a la lectura política de la novela, la crítica ha confundido en el concepto de "barbarie" dos nociones enfrentadas de pueblo. Sin embargo, sólo una de ellas constituye la barbarie propiamente dicha, en el sentido que Gallegos le confiere a este término. Así, en la novela observamos que está el pueblo "luzardero" (162) o "altamireño" (188), es decir, el que se muestra leal a Santos Luzardo y acepta ser integrado al orden liberal y civilizado que él promueve. Ser "luzardero" no significa solo trabajar en el hato de Altamira o estar a las órdenes de Santos, sino sobre todo respetar un cierto orden de lo sensible. Por eso el viejo Melesio Sandoval puede afirmar: "luzardero nací y en esa ley tengo que morir" (162). El sector del pueblo que respeta esta ley, al que podemos llamar "pueblo bueno" o "pueblo luzardero", es un pueblo dócil y trabajador que anhela ser liderado por Santos en la medida en que él encarna la misma ética esencial que a ellos les caracteriza. Una ética natural que se define por el establecimiento de una continuidad entre los contrarios y por el respeto al

5 Sobre el vínculo del tremedal con el exceso, véase González Echevarría 2001: 97. 
término medio. De ahí que los peones "luzarderos" sean caracterizados en la novela por la armonía que establecen entre el adentro y el afuera. Por ejemplo, Juan Palacios, apodado Pajarote, al ser presentado a Santos Luzardo, dice al respecto: "no soy de la casa desde tiempo inmemorial, como usted acaba de decir, pero conmigo puede contar para todo lo que se le ofrezca, porque yo no soy sino lo que se me ve por encima" (170. Subrayado nuestro). De la misma manera, cuando la estancia de Santos en el Llano empieza a surtir efecto en su carácter, se empieza a producir también en él una conjunción entre lo interior y lo exterior. Así, nos dice el narrador: "bajo la salvaje algarabía de las aves que doran sus alas en la tierna luz del amanecer [...] palpita con un ritmo amplio y poderoso la vida libre y recia de la llanura. Santos Luzardo contempla el espectáculo desde el corredor de la casa y siente que en lo intimo de su ser olvidados sentimientos se le ponen al acorde de aquel bárbaro ritmo" (195. Subrayado nuestro). Es precisamente este pueblo solícito y obediente el que permite la síntesis entre la élite y el pueblo, entre la ciudad y el campo, que ha puesto de manifiesto la mayor parte de la crítica sobre la novela.

Ahora bien, esta síntesis entre civilización y barbarie, que sin duda se cumple de manera exitosa en la novela, este "nosotros" liberal y mestizo que constituye el orden social y político que promueve la obra, sólo se puede construir a través de la definición de un "ellos" que queda necesariamente fuera del consenso. Llegamos así a la auténtica noción de "barbarie" que pone en juego la novela: una barbarie que resulta completamente inasimilable pero que ayuda desde fuera a definir el ideal político y social que la obra defiende. El verdadero antagonismo en la novela se establece entonces entre los amigos (Santos y el pueblo "bueno", asimilable al proyecto liberal de las élites) y los enemigos absolutos o injustos (doña Bárbara y sus secuaces, agrupados bajo el apelativo de "miedeños"). Y es este otro-radical —que resulta inasimilable por el proyecto hegemónico de Santos Luzardo y que ocupa, por lo tanto, el lugar del "no-sujeto"- 6

6 Moreiras (2006: 81) ha indicado que este no-sujeto es la condición de posibilidad de toda política. El teórico español insiste así en una idea que ha abordado también Jacques Rancière, para quien este sector del pueblo inasimilable constituye el verda- 
el que define en la obra el concepto de "barbarie". La descripción de $E l$ Brujeador que aparece en el primer capítulo de la novela -titulado, característicamente, "¿Con quién vamos?"-, nos puede servir para observar la distancia que se establece entre los pobladores del Llano, que sí resultan adecuados para el proyecto políitico que toma forma en la novela, y los sujetos que deben quedar fuera del mismo:

Su compañero de viaje [el compañero de viaje de Santos] es uno de esos hombres inquietantes, de facciones asiáticas, que hacen pensar en alguna semilla tártara caída en América quién sabe cuándo ni cómo. Un tipo de razas inferiores, crueles y sombrías, completamente diferente del de los pobladores de la llanura. Va tendido fuera de la toldilla, sobre su cobija, y finge dormir; pero ni el patrón ni los palanqueros lo pierden de vista (118. Subrayado nuestro).

Este sector del pueblo, en el que se cuentan doña Bárbara y sus adeptos, se caracteriza por la deslealtad y por la incapacidad para alcanzar la síntesis de los opuestos; por eso muestra siempre una disociación entre el adentro y el afuera. Así, en otro pasaje de la obra, El Brujeador es caracterizado como "uno de esos sujetos tortuosos y agazapados que siempre necesitan manifestar todo lo contrario de lo que sienten. Sus ademanes blanduzcos, sus palabras calmosas y su costumbre de mostrarse siempre muy admirado de la hombría de los demás envolvían una maldad buida y fría que traspasaba los límites de lo atroz" (178. Subrayado nuestro). De la misma manera, el mayordomo Balbino Paiba, "era traidor por naturaleza" (370) y robaba el ganado a la propia doña Bárbara. Esta disociación en el carácter les vuelve socialmente inasimilables, ya que sólo entienden los extremos

dero "pueblo": "El pueblo es la existencia suplementaria que inscribe la cuenta de los incontados o la parte de los sin-parte [...]. No es el populacho laborioso y sufriente quien viene a ocupar el terreno del actuar político y a identificar su nombre con el de la comunidad. Lo que es identificado por la democracia con el todo de la comunidad es una parte vacía, suplementaria, que separa la comunidad de la suma de las partes del cuerpo social. Esta separación primera funda la política como acción de sujetos suplementarios que se inscriben como excedente con respecto a toda cuenta de las partes de la sociedad" (Rancière 2007: 67). 
del sometimiento o la traición. Por eso, en otra ocasión se dice que $E l$ Brujeador "tenía el alma del espaldero genuino, que no es un hombre cualquiera, sino uno muy especial, en quien tienen que encontrarse reunidas dos condiciones que parecen excluirse: inconsciencia absoluta y lealtad a toda prueba" (370. Subrayado nuestro). Esta falta de armonía interior, además de impedir a estos "no-sujetos" reconocer y encarnar la ética esencial que caracterizaba al otro sector del pueblo, era resultado de su falta de educación y les impedía ser incorporados al proyecto civilizatorio. $^{7}$ A este sector del pueblo radicalmente bárbaro no se le puede educar y, por lo tanto, en la visión de Gallegos, tampoco se le puede gobernar. Sin embargo, este enemigo radical, absolutamente bárbaro y, por eso, inasimilable, permite que el proyecto civilizatorio defina completamente sus contornos y se conforme a sí mismo como una totalidad coherente. Doña Bárbara y los "miedeños", es decir, el pueblo que queda más allá de toda ética y de toda reglamentación, constituyen el suplemento social que per-

7 En relación con esto se puede recordar que la propia llanura, al igual que doña Bárbara, "está llena de espejismos" (217. Subrayado nuestro). La falta de armonía que es visible en el carácter y en la conducta de los enemigos de Luzardo se aprecia también en un nivel social. En un momento en que Santos está reflexionando sobre la falta de ley en el Llano, Mujiquita le ofrece ir a tomar "un palo", y Santos afirma entonces: "-También es verdad que no existirían ño Pernaletes si no existieran... Iba a decir: Mujiquitas; pero comprendió que aquel infeliz era también una víctima de la barbarie devoradora de hombres, y con la ira ya trocada en compasión le respondió su invitación de inconsciente: -No, Mujiquita. Todavía no empezaré a beber aguardiente" (391). Santos Luzardo rechaza así la falta de armonía social y denuncia la imposibilidad de la síntesis, la existencia de extremos que se corresponden. Sin embargo, no culpa a Mujiquita sino a la barbarie que reinaba en el Llano y que era necesario superar. La existencia de extremos sociales complementarios había sido denunciada por el propio Rómulo Gallegos en un texto sobre la educación venezolana: "Otra de aquellas muchas cualidades de que a menudo nos lamentamos, es esta típica forma compleja de nuestro carácter, mezcla de servidumbre y rebeldía, que en todas las fases de nuestra vida, individual o social, nos adscribe como voluntades subversivas a toda ley o principios de autoridad, al propio tiempo que como siervos sumisos del hombre en quien encarna la entidad abstracta de aquellas mismas ley o autoridad desconocidas. Aspecto de nacionalidad incipiente o atavismos de razas de señores y siervos confundidas, esta peculiar condición, fecunda causa de males para la sociedad, es cultivada en nuestros hogares y escuelas" (Gallegos 1977: 1610-1611). 
mite por contraste la creación de una nacionalidad mestiza y homogénea, en que las élites dirigirán al pueblo "bueno". Este otro-radical se sustrae a la posibilidad del mestizaje, pero, al mismo tiempo, marca el límite que lo hace posible. Por ello, además, no será completamente exterminado, sino que, como veremos más adelante, persistirá como una amenaza fantasma capaz de clausurar por sí sola y en cualquier momento el proyecto hegemónico liberal-popular que la novela promueve.

Una vez explicada la diferencia entre el pueblo bueno y la barbarie, se entienden mejor las dos posiciones de la crítica a las que se refería Javier Lasarte, y que hemos señalado al principio de este artículo. Ambas perspectivas tienen sentido y, por lo tanto, no son antagónicas sino complementarias. Un sector de la crítica habría privilegiado una interpretación según la cual en la novela se cumpliría una síntesis exitosa entre la élite, personificada en la figura de Santos Luzardo, y el pueblo "luzardero". Otro sector de la crítica, en cambio, habría sido más sensible a la relación antagónica que se da en la novela (civilización versus barbarie) y, sin negar la posibilidad de síntesis dialéctica, ${ }^{8}$ habría hecho más hincapié en el triunfo (o en la "conquista") de la civilización sobre la barbarie radical, representada por doña Bárbara y los "miedeños". Ahora bien, al no enfocar su lectura en términos políticos, este sector de la crítica tampoco habría sido capaz de delimitar bien los bandos en conflicto y de extraer las consecuencias de

8 Incluso la crítica que prefiere una lectura de la novela a partir de la oposición civilización-barbarie, reconoce la pertinencia de las lecturas que hacen énfasis en la síntesis de los términos enfrentados. Por ejemplo, Doris Sommer ha afirmado que "Gallegos y sus críticos reconocen que Santos, el ciudadano civilizador, tiene que aprender algo sobre la capacidad para defenderse y la violencia necesaria (yo añadiría pasión) de Bárbara (Gómez) antes de reemplazarla. Esta es sin duda una lectura admisible; y resuelve fácilmente la aparente falta de conexión entre el año de la novela y su referente económico" (2004: 356. Subrayado nuestro). José Castro-Urioste, después de analizar la bibliografía más importante sobre la novela, indica igualmente que "de estas lecturas será conveniente retomar la interpretación que asume que Doña Bárbara no expresa la aniquilación total del 'otro' como en Facundo, sino que valora ciertos elementos de aquél. 'Civilización' y 'barbarie', como los personajes que encarnan la dicotomía, incluyen mutuamente en su representación rasgos que pertenecen a su opuesto. Doña Bárbara transforma la visión maniquea de Sarmiento y, a su vez, la enriquece" (1994: 132). 
este enfrentamiento. ${ }^{9}$ En ese sentido, la crítica no ha interpretado con profundidad el significado de los términos civilización-barbarie en la novela y ello le ha impedido comprender que el verdadero antagonismo que ella pone en juego se analiza mejor como una confrontación amigo-enemigo. Esta confrontación tiene como objetivo fundar un orden social homogéneo, liberal y mestizo, que conlleva la exclusión de cualquier exceso o suplemento. La miopía de la crítica a este respecto sería resultado de la propia novela, pues ella plantea la confrontación nosotros-ellos como una oposición moral entre el bien y el mal, de manera que el oponente solo puede ser visto como un enemigo que debe ser destruido.

\section{SANTOS Y BÁRBARA}

El enfrentamiento entre el proyecto civilizatorio que incluye al pueblo "bueno" y la barbarie radical se establece, además y sobre todo, en el nivel de los líderes de ambas tendencias: Santos Luzardo y doña Bárbara. Estos personajes encarnan respectivamente los valores de la hegemonía que promueven y la pugna entre los dos sintetiza, de alguna manera, los repartos de lo sensible que tienen lugar en la propia novela. "The struggle between Luzardo and doña Bárbara - señala Carlos J. Alonso- is itself the vehicle through which the larger strife between civilization and barbarism is enacted" (Alonso 1989: 430). En efecto, las relaciones entre ambos resumen de alguna manera el enfrentamiento político que se establece entre la voluntad de conformar un orden (Santos) y el suplemento que excede

9 Por ejemplo, Castro-Urioste ha hablado de "dos planos" en la "conquista" que lleva a cabo Santos Luzardo pero no ha explicado este doble plano a partir de las dos nociones de "pueblo" que pone en juego la novela. Dice Castro-Urioste: "La plenitud de la 'conquista' se expresa en dos planos. Hay una 'conquista' social reflejada en la lucha contra doña Bárbara y en la imposición de la 'cerca' como símbolo de un sistema intensivo de explotación. Junto a esta 'conquista' coexiste otra ejemplificada en la relación de Santos con Marisela como también -de alguna manera- con doña Bárbara. Por consiguiente, Luzardo realiza una doble 'conquista': una sentimental, amorosa, y otra, social y laboral" (1994: 135). 
toda noción de orden pero que ayuda a fundarlo (doña Bárbara). En el nivel alegórico al que la propia novela remite constantemente, se puede decir que Santos Luzardo representa el orden legal y cultural, mientras que doña Bárbara simboliza la falta de límites y el exceso, y queda vinculada así al orden de la naturaleza. ${ }^{10}$

Para Santos (y también para la voz narrativa), la sociedad debe someterse al imperio de la ley y de la gramática. Tal es la importancia que Luzardo concede a las leyes, cuya necesidad de acatarlas defiende incluso a sabiendas de que éstas han sido promulgadas arbitrariamente. Así, en un momento en que el peón Antonio Sandoval le cuenta a Santos Luzardo algunos de los desmanes de doña Bárbara en Altamira y le sugiere la conveniencia de reconstruir "la posteadura", el abogado responde lo siguiente:

- No hay que precipitarse. Antes necesito estudiar las escrituras de Altamira para determinar el lindero y consultar la Ley del Llano.

- ¿La Ley del Llano? -replicó Antonio socarronamente-. ¿Sabe usted cómo se la mienta por aquí? Ley de doña Bárbara. Porque dicen que ella pagó para que se la hicieran a la medida.

- No tendría nada de extraño, según andan las cosas por aquí -dijo Santos-. Pero mientras sea ley, bay que atenerse a ella. Ya se procurará reformarla (231. Subrayado nuestro).

Asimismo, Santos considera que el buen orden social y el respeto a la ley están vinculados con la propiedad del habla y de la escritura. De ahí su insistencia en mejorar la expresión oral de Marisela, pues para él la corrección lingüística representa un alto grado de civilidad. En el capítulo "Los amansadores", la educación de Marisela se compara con la doma de la yegua Catira, y en este proceso educativo es constante la corrección del vocabulario de la niña:

- Déjeme ir para mi monte otra vez.

- Vete, pues. Pero hasta allá te perseguiré diciéndote: no se dice jallé, sino hallé o encontré; no se dice aguaite, sino mire, vea.

10 Siguiendo a Carl Schmitt, Alberto Moreiras (2006: 56-57) ha analizado la subsunción de la naturaleza por la cultura como un síntoma del triunfo absoluto del liberalismo. 
$[\ldots]$

- iGuá! ¿Qué voy a querer yo? ¿Acaso estoy pidiendo más, pues?

- iEl guá, otra vez!

- iUmjú!

- No te impacientes - concluyó él-. Te llevo la cuenta de los guás y todos los días la cifra va disminuyendo. En todo el de hoy una sola vez se te ha escapado.

Esto en cuanto al vocabulario, corrigiéndoselo a cada momento. Las lecciones, propiamente eran por las noches. [...] En cuanto a las maneras y costumbres, los modelos eran señoritas de Caracas, todas bien educadas y exquisitas, amigas de Santos, siempre oportunamente recordadas en las conversaciones con que él animaba las sobremesas (267-268). ${ }^{11}$

La relación entre civilidad y propiedad lingüística se aprecia también en el rechazo de Santos a la manera en que No Pernalete impartía justicia. El juez del distrito ejerce su poder de forma arbitraria y denomina a esa manera de ejercerlo

"poner los puntos sobre las haches": "¿Usted no conoce el cuento? Se lo voy a echar, porque es cortico. Era uno de esos hombres a quienes llaman brutos, pero que tenía el tonto muy lejos. No conocía la ortografía y no decía halar, sino jalar, ni hediondo, sino jediondo, y cuando su secretario [...] le ponía con hache una de esas palabras que a él no le sonaban sino con jota, le decía: 'Está bueno, pero. . . ipóngame un punto a esa hache!'” (389).

Una vez escuchada esta explicación del magistrado, y "mientras Mujiquita le reía la ocurrencia al general", Santos replicó: "-Si ésa es la or-

11 A pesar de lo que pudiera parecer por esta cita, la relación entre Santos y Marisela no es asimétrica, sino más bien simbiótica: "Así, pues, mientras él la iba desbastando de su condición silvestre, Marisela le servía de defensa contra la adaptación a la rustiquez del medio, fuerza incontrastable con que la vida simple y bravía del desierto le imprime su sello a quien se abandona a ella" (270). La pareja encarna así la unidad de los contrarios que se da también a nivel individual en la figura de Santos. Y la educación de Marisela revierte positivamente en el propio Santos, impidiéndole caer en la barbarie. Así, hacia el final de la novela, cuando Santos sucumbe momentáneamente a la atracción de la barbarie, Antonio le pide a Marisela que vuelva a Altamira para que así su amo recupere el camino de la virtud (415-416). Es además Marisela quien explica a Santos que fue Pajarote y no él quien asesinó a El Brujeador, con lo que salva a Santos de la caída definitiva en el lado del mal y de la barbarie (443). 
tografía que se usa por aquí, he perdido mi tiempo al venir a impetrar justicia" (389. Subrayado nuestro).

Además de defender la idea de límite en todas sus formas, Santos Luzardo representa la mesura y la capacidad de síntesis dialéctica, es decir, el virtuoso término medio entre los opuestos. De esta forma, él encarna una virtud esencial que permite operar el paso de lo particular a lo universal y que constituye el ideal social, político y cultural que la novela promueve. Él es el hombre letrado y urbano, pero para hacerse con el liderazgo del pueblo bueno y ser capaz de representarlo y guiarlo, tendrá que recuperar su herencia llanera y demostrar que él encarna el término medio entre la pasión y la inteligencia. Así, cuando Santos llega por fin a la casa de Altamira y analiza sus sentimientos, se da cuenta de que en ellos se mezclaban "dos corrientes contrarias: propósitos e impulsos, decisiones y temores":

Por una parte, lo que había sido fruto de reflexiones ante el espectáculo de la llanura: el deseo de consagrarse a la obra patriótica, a la lucha contra el mal imperante, contra la Naturaleza y el hombre, a la búsqueda de los remedios eficaces [...]. Pero en aquella decisión hubo también mucho del impulsivo escapado de la disciplina del razonador, al contacto con el medio propicio: la llanura semibárbara [.. . ], pues bastó que el bonguero ponderase los riesgos que corría quien intentara oponerse a los planes de doña Bárbara para que él desistiese de su propósito de vender el hato (171).

Además de encarnar el término medio, lo que en la visión de Gallegos permite unir los opuestos y hallar lo universal, Santos es un sujeto sin aristas o puntos ambiguos: él tiene una identidad genérica definida, como demuestra en el episodio de la doma (200), y es un sujeto que respeta el orden familiar, además de promover las buenas maneras y la citada corrección lingüística. El impacto de la presencia de Santos Luzardo en el Llano se cumple entonces a través de un doble movimiento que es complementario: por un lado, armoniza los opuestos, y, por el otro, impone cercas físicas y simbólicas a la barbarie:

Luzardo se quedó pensando en la necesidad de implantar la costumbre de la cerca. Por ella empezaría la civilización de la llanura; la cerca sería el derecho contra la acción todopoderosa de la fuerza, la necesaria limitación 
del hombre ante los principios [...]. El hilo de los alambrados, la línea recta del hombre dentro de la línea curva de la Naturaleza, demarcaría en la tierra de los innumerables caminos, por donde hace tiempo se pierden, rumbeando, las esperanzas errantes, uno solo y derecho hacia el porvenir $(233-234)$.

Por lo demás, la influencia de Santos Luzardo en el Llano no procede tanto de un ideario concreto expresado discursivamente, como de su capacidad para encarnar un ethos y generar una nueva afectividad. Los afectos que Santos Luzardo pone en juego tendrán efectos sobre todos los habitantes del Llano, incluida la misma doña Bárbara, como veremos más adelante. Sin embargo, es quizás en la figura de Marisela donde el contacto con el abogado da lugar a la transformación más profunda. Después de que Santos, en el primer encuentro educativo con Marisela, le da una serie de consejos en cuanto a su higiene física y verbal, el narrador afirma lo siguiente:

las manos le lavaron el rostro y las palabras le despertaron el alma dormida. [Marisela] Advierte que las cosas han cambiado de repente. Que ella misma es otra persona. [...] Él le ha dejado dos cosas tiernas. La frescura del agua en las mejillas, que ahora le están produciendo sensaciones desconocidas. iSí se siente la belleza! [...] Le ha dejado, también, la emoción de unas palabras nunca oídas hasta entonces. [...] También fuera de ella ya el mundo no es lo que hasta allí había sido: un monte intricado donde recoger chamizas, un palmar solitario donde era posible estar horas y horas [...] sin emociones ni pensamientos. Ahora los pájaros cantan y da gusto oírlos, ahora el tremedal refleja el paisaje [... la belleza no está en ella solamente; está en todas partes [...] iY ella no se había dado cuenta de que todo esto existía, creado para que lo contemplaran sus ojos! (226).

Las enseñanzas de Santos permiten a Marisela descubrir el mundo y adquirir una percepción estética del mismo. La transformación de los modales de la niña se traduce así en una intelección más profunda de lo real, con lo que Gallegos parece plantear que ser educado cívicamente conduce a un estadio superior de lo humano.

Por su parte, el personaje de doña Bárbara encarna un ethos radicalmente contrario al de Santos Luzardo, pues ella se caracteriza por estar 
más allá de cualquier noción de límite y por anular así toda posibilidad de síntesis dialéctica. ${ }^{12}$ Ya desde su mismo origen ella está vinculada con la infinitud: "iDe más allá del Cunaviche, de más allá del Cinaruco, de más allá del Meta! De más lejos que más nunca - decían los llaneros del Arauca, para quienes, sin embargo, todo está siempre 'ahí mismito, detrás de aquella mata'-. De allá vino la trágica guaricha. [...] su origen se perdía en el dramático misterio de las tierras vírgenes" (141). Y su propio carácter constituye una mezcla anárquica de contrarios culturales que no presenta ningún atisbo de orden o de armonía:

...en su espíritu, hechicería y creencias religiosas, conjuros y oraciones, todo estaba revuelto y confundido en una sola masa de superstición, así como sobre su pecho estaban en perfecta armonía amuletos de los brujos indios y escapularios [...]. Tocante a amores, ya ni siquiera aquella mezcla salvaje de apetitos y odio de la devoradora de hombres. Inhibida la sensualidad por la pasión de la codicia y atrofiadas hasta las últimas fibras femeniles de su ser por los hábitos del marimacho, [...] si alguna razón de pura conveniencia [...] la movía a prodigar caricias, más era hombruno tomar que femenino entregarse. Un profundo rencor por el hombre había reemplazado al rencor implacable. [...] Tal era la famosa doña Bárbara: lujuria y superstición, codicia y crueldad, y allá en el fondo del alma sombría una pequeña cosa pura y dolorosa: el recuerdo de Asdrúbal, el amor frustrado que pudo hacerla buena (153-154).

Doña Bárbara - a la que el narrador se refiere en una ocasión como "demonio andrógino" y cuya alma, aduce, simboliza la "monstruosidad de la Naturaleza" (288) - , representa el exceso en todas sus formas: tiene una identidad genérica ambigua, es un marimacho que busca someter al varón; además, funda su poder en la superstición y en la falta de racionalidad. Por eso, a pesar de lo que pudiera parecer, el narrador aclara que las acciones de la cacica no responden a un designio consciente, sino que son resultado del azar y de la impulsividad:

12 En esta interpretación coincidimos con Roberto González Echevarría, quien ha indicado que "doña Bárbara es la fuerza diseminatoria que impulsa la novela" (2001: 102). 
Así, por momentáneos impulsos aislados, que luego circunstancias fortuitas encadenaban, había procedido siempre, y como casi siempre la había ayudado la fortuna, visto por fuera -y era así como ella misma lo veíaaquello parecía efectiva y extraordinaria previsión; mas, visto por dentro, doña Bárbara resultaba incapaz de concebir un verdadero plan. Su habilidad estaba, únicamente, en saber sacarle enseguida el mayor provecho a los resultados aleatorios de sus impulsos (252).

De la misma manera, doña Bárbara no muestra ningún respeto por la propiedad privada ni tampoco por la economía de mercado, ya que su riqueza se basa en la simple acumulación y no en la inversión: "Y mientras las tierras limítrofes iban incorporándose de este modo a su feudo, y la hacienda ajena engrosaba sus rebaños, todo el dinero que caía en sus manos desaparecía de la circulación. [... ella para apreciar su dinero no lo contaba sino lo medía" (152). A lo largo de la novela se aprecia igualmente que Bárbara rechaza toda noción de responsabilidad familiar o grupal, pues a ella sólo le interesa su voluntad de poder, su ambición individual:

Artera fue la táctica empleada por doña Bárbara cuando recibió aquella carta donde Luzardo le participaba su determinación de cercar Altamira. Nada podía agradarle menos que esta noción de límite a quien, cuando se le ponderaba su ambición de dominio, solía replicar socarronamente: -Pero si yo no soy tan ambiciosa como me pintan. Yo me conformo con un pedacito de tierra nada más: el necesario para estar siempre en el centro de mis posesiones, donde quiera que me encuentre (249).

Por todo ello es evidente que, frente a la mesura y la voluntad de orden que representa Santos Luzardo, la "devoradora de hombres" muestra una falta absoluta de ponderación y de respeto por los límites. ${ }^{13}$ Mientras que el abogado es un héroe clásico, respetuoso de la ley y de lo finito,

13 Doris Sommer ha señalado respecto de la oposición Santos-Bárbara en los mismos términos que nosotros: "Fronteras, cercas y definiciones fijas son los primeros requisitos de la civilización, el tipo de escritura que hasta los más bárbaros han de entender. Lo indefinible era precisamente la transgresión semiótica que le daba al llano su encanto seductor, con su círculo alucinatorio de espejismos que se esfuman y la sexualidad desorbitada de Bárbara" (2004: 352). 
doña Bárbara es más bien una heroína romántica y nietzscheana, capaz de superar todas las cercas -las espaciales y las simbólicas- y de sobreponerse a las nociones del bien y del mal. Resulta probado, entonces, que también al nivel de los líderes que representan las dos opciones hegemónicas se da una oposición entre el sometimiento al orden, y el suplemento que excede ese orden pero que ayuda a fundarlo o definirlo desde fuera.

Conviene aclarar, como hemos indicado antes, que la lucha por la hegemonía se plantea sobre todo desde el plano de los afectos y no desde el plano discursivo: tanto Santos como doña Bárbara ponen en juego dos formas opuestas de afectividad y será precisamente en el campo de los afectos donde se produzca la victoria del primero sobre la segunda. Esto revela que Gallegos era consciente de la gran incidencia que tienen "las fuerzas afectivas" "en el origen de las formas colectivas de identificación" y de la importancia del "Eros" para mantener la cohesión de la comunidad (Mouffe 2011: 34). Es evidente que la llegada de Santos al Llano supone un verdadero acontecimiento, en la medida en que su presencia y sus actos (más que su discurso) inauguran un nuevo espacio social. La afectividad que genera la presencia de Santos no sólo tiene efectos sobre el pueblo bueno, que le sigue convencido, sino que es capaz de transformar a la propia doña Bárbara que siente una atracción irresistible por el dueño de Altamira. La capacidad del abogado para establecer una unidad entre los contrarios y para imponer límites físicos y simbólicos, transforma a la dueña de El Miedo:

[...] ella, al oír aquellas palabras correctas, pero al mismo tiempo secas, casi no se daba cuenta de lo que respondía. La subyugaba aquel insólito aspecto varonil, aquella mezcla de dignidad y de delicadeza que nunca había encontrado en los hombres que la trataran, aquella impresión de fortaleza y dominio de sí mismo que trascendía del fuego reposado de las miradas del joven, de sus ademanes justos, de sus palabras netamente pronunciadas (285).

Doña Bárbara siente la superioridad de los valores que encarna Santos y su sola presencia le hará cambiar de actitud y recuperar lo que, de acuerdo al planteamiento de la novela, sería una identidad genérica nor- 
malizada, es decir, una identidad puramente femenina ya y sometida al imperio de la ley y de la mesura. ${ }^{14}$ Así, la figura de Santos permite que, hacia el final de la novela, la "devoradora de hombres" vuelva a ser esa mujer inocente y esencial, anterior al asesinato de Asdrúbal y a la violación que sufrió en su primera juventud. Aquella violencia desencadenó la individualidad desmesurada y excesiva que ella representa y, en el largo plazo, la problemática social que expone la novela. En última instancia, el orden liberal y el amor que Santos encarna se imponen sobre la violencia y la arbitrariedad de doña Bárbara, y la historia vuelve al principio con la unión de Santos y Marisela. En este sentido, la novela parece proponer un regreso nostálgico al momento utópico del primer amor anterior al conflicto narrado. Este retorno romántico se plantea en la obra a través del paralelismo que se establece entre la pareja Asdrúbal-Bárbara y la unión de Santos y Marisela, pero también a través del mensaje que "el Socio" le había comunicado a doña Bárbara y que ésta se repite en varias ocasiones

14 Esta nueva manera de sentir de Bárbara está vinculada al hecho de que Santos cumple la ley y obliga a cumplirla: "Santos estudió cuidadosamente el asunto antes de proceder a plantar la posteadura de la cerca, y cuando aquella vio que la plantaba justamente donde debía, sin caer en el ardid, tuvo la intuición de que algo nuevo comenzaba para ella desde aquel momento" (252. Subrayado nuestro). En este otro fragmento se aprecia que la actitud de doña Bárbara está vinculada con el acatamiento de los límites: "lo que más le encrespaba la cólera era que fuese, precisamente, aquella ley suya, pagada con su dinero, lo que la obligase a otorgar cuanto se había propuesto negar. Estrujó rabiosamente la hoja del follero murmurando: -iQue este papel, este pedazo de papel que yo puedo arrugar y volver trizas, tenga fuerza para obligarme a hacer lo que no me da la gana! Pero estas rabiosas palabras, además de encono, expresaban también otra cosa: un acontecimiento insólito, un respeto que doña Bárbara nunca babía sentido" (263. Subrayado nuestro). Julie Skurski también ha relacionado la transformación que se opera en doña Bárbara con la afectividad que la presencia de Santos introduce en el Llano y, en concreto, con la noción de límite: "Doña Barbara's encounter with Luzardo unexpectedly transforms her, as she responds to him unconsciously as the incarnation of her murdered love and, correspondingly, as the enlightened "law" that she desires. Aware that she is becoming domesticated and feminine, Doña Barbara reflects upon herself in a rare moment of introspection. She acknowledges the destabilizing effect on her identity of her desire for Luzardo, telling him, 'If I had encountered men like you in my path before, my story would be a different one'" (1994: 623). 
hacia el final de la novela: "Las cosas vuelven al lugar de donde salieron" $(374,460)$.

En relación con este aspecto hay que señalar que, si bien la mayoría de los personajes "miedeños" se marchan o son asesinados por la acción de los "altamireños", la devoradora de hombres tiene un final deliberadamente ambiguo, pues el narrador no aclara si muere o si simplemente desaparece, aunque esta última opción parece la más probable:

La noticia corre de boca en boca: ha desaparecido la cacica del Arauca. Se supone que se haya arrojado al tremedal, porque hacia allá la vieron dirigirse, con la sombra de una trágica resolución en el rostro; pero también se habla de un bongo que bajaba por el Arauca y en el cual alguien creyó ver una mujer. [...] Pero como era cosa sabida que tenía mucho oro enterrado y de esto nada decía la carta, y, además, en el cuarto de las brujerías se encontraron señales de desenterramientos, a la presunción de suicidio se opuso la de simple desaparición, y se habló mucho de aquel bongo que, navegando de noche, ya eran varias las personas que lo habían visto pasar, Arauca abajo (476).

Frente al orden social homogéneo que representa la unión armónica de Santos y Marisela, el fantasma de doña Bárbara será un exceso siempre ausente y siempre presente, cuya reaparición potencial permitirá por mucho tiempo la cohesión de la nación homogénea y mestiza. ${ }^{15}$ De tal

15 Con respecto a la desaparición de doña Bárbara, la crítica ha planteado interpretaciones dispares, ninguna de las cuales coincide con la nuestra. Javier Lasarte, por ejemplo, la interpreta como un acto de "nobleza" de la cacica: "Pero el pacto populista se sellará definitivamente con el acto de mayor nobleza: la voluntaria desaparición de doña Bárbara. Santos es quien reactiva en Bárbara el recuerdo de las bondadosas palabras de Asdrúbal, pero será ella paradójicamente quien, con su benéfica mentira y su sacrificio de sí, lo salve de la barbarie y lo redima ante la ley. La renuncia a ser lo que pudo ser, a una nueva vida guiada por el amor, su vuelta al tremedal, es su decisión de acabar con el mal impreso en su cuerpo para hacer posible la nación mestiza, Santos y Marisela. Su muerte alegórica es el parto del pacto nacionalista. Son los gestos de la eficaz alianza con lo social y culturalmente diferente, ahora convertido en la gran familia de Altamira/nación o de la nación de Alta-mira" (2011: 50). Por su parte, Julie Skurski interpreta la desaparición de Bárbara de una manera diferente: "But as the 
manera que el movimiento contrahegemónico que Santos promueve en el Llano se impone totalmente, y esto se consigue a través de la derrota del bando contrario, constituido por doña Bárbara y sus seguidores. El ethos liberal, que se ampara en el respeto a la ley y a la escritura, toma en la novela la forma de un enfrentamiento entre el bien y el mal que justifica la destrucción del contrario y que, al asegurar el vínculo entre las élites y el pueblo bueno, conduce a una suerte de fin de la historia. Para lograr este consenso, es imprescindible la presencia del suplemento representado por doña Bárbara y los "miedeños", el cual será prácticamente eliminado, aunque perdurará como una presencia fantasmal para asegurar la identidad del "nosotros" y la igualdad de la sociedad consigo misma. Sin este otro-radical, fundando el consenso desde la sombra, la sociedad podría quebrarse desde dentro. Por ello no es casualidad que Doña Bárbara sea además el título de la obra.

\section{ESTÉTICA Y POLÍTICA}

La pugna entre la totalidad y el exceso que permite conformar la hegemonía luzardera y el orden social liberal-populista que promueve la novela, se aprecia, asimismo, en la propia anécdota y en la concepción del lenguaje. En cuanto a la historia narrada, hemos observado cómo la unión de Santos y Marisela al final de la obra supone la reunificación de la pareja Asdrúbal-Bárbara y por lo tanto una vuelta a la situación inicial. El tiempo entonces es eterno retorno y la violencia que dio origen a la naturaleza desmesurada de doña Bárbara y con ella, a la propia ficción narrativa, se redime en la nueva pareja. La propia trama sería entonces una conjuración de la violencia que está en su origen y concluye precisamente cuando esta violencia original se ha superado y se ha cumplido a un tiempo la

ambiguous ending suggests, with its evocation of indigenous beliefs in hidden water spirits, Dona Barbara remains as a submerged presence. She lives on in legend and fantasy, a symbol of seductive primal instincts within leader and pueblo alike" (1994: 624). 
unión amorosa y política. ${ }^{16}$ El consenso social que promueve la novela tiene su doble estructural en la circularidad de los hechos narrados: tanto la anécdota como el ideal político que la novela propone concluyen con una sutura que deja fuera a ese otro (la violencia, el exceso) que ha permitido fundarlos. Ni la trama ni el orden social deben admitir cuerpos de más, sino que deben cerrarse sobre sí mismos ante la amenaza anárquica que las funda, respectivamente, desde el principio (la violencia contra Asdrúbal y Bárbara) y desde el exterior (los enemigos radicales que amenazan el orden social).

De manera semejante, la actitud de Rómulo Gallegos con respecto al lenguaje revela un intento obsesivo de controlar la proliferación potencial de la significación. Como ha indicado Doris Sommer, "no es que Gallegos ignorara la naturaleza inestable del lenguaje - de hecho lo atormentaba-, sino que la trata como un peligro, no como fatalidad". ${ }^{17}$ En la visión de Gallegos, en efecto, el lenguaje es un exceso que, como los demás elementos sobrenumerarios que pone en juego la novela, debe ser conjurado y regulado. Esta concepción de Gallegos con respecto al lenguaje se aprecia, por ejemplo, en el recurso permanente de la alegoría. Según lo ha estudiado Carlos J. Alonso, siguiendo a su vez la interpretación de Roberto González Echevarría, Doña Bárbara sería algo semejante a un "roman à thèse" en la medida en que explicita constantemente cómo debe ser interpretada, esto es, como un enfrentamiento entre la civilización y la barbarie. Esta auto-interpretación de la obra se realiza a través de la "allegoresis", cuya intención es conseguir que los significantes presentes remitan siempre a los significados originarios y asegurar así que las palabras no digan nada más que aquello que deben decir. Sin embargo, según el propio Carlos J. Alonso, esta búsqueda obsesiva de legitimidad en la propia narración

16 Con base en esta relación entre unión amorosa y unión política, Doris Sommer ha interpretado Doña Bárbara como una "ficción fundacional". Ella ha indicado específicamente que Doña Bárbara y La vorágine serían "revisiones populistas del romance" que consistirían en la "defensa de la nación establecida frente a las relaciones transgresoras" (2004: 14).

17 En este fragmento, Doris Sommer alude a Roberto González Echevarría en su análisis sobre el lenguaje en la novela (2004: 360). 
estaría ocultando una inseguridad con respecto al significado de la misma, la cual justificaría la necesidad de leer mal Doña Bárbara y de denunciar su aparente simplicidad.

El intento obsesivo de conjurar el exceso constitutivo del lenguaje se aprecia, asimismo, en el control que el autor ejerce sobre el habla del Llano. Como ha indicado José Castro-Urioste, en esta novela "la forma escrita [...] aparece como el instrumento de integración y sometimiento del 'otro'. En este sentido, en Doña Bárbara se recopila la 'voz' de la 'periferie' (y en ciertos casos se admira), pero se mantiene la escritura como el instrumento que debe homogeneizar y dirigir a las otras "voces"' (1994: 137). ${ }^{18}$ Así, por ejemplo, la inclusión de un diccionario de venezolanismos al final de la obra muestra que si las palabras de los llaneros debían formar parte de la narración, su significado debía estar controlado y legalizado por la conciencia letrada. De la misma manera que el "pueblo bueno" debía entrar en el orden social liderado por las élites, su palabra podía acceder al acervo de la lengua común, siempre que hubiera sido previamente pautada y controlada.

Una posición semejante se percibe con respecto al arte y las creencias populares, pues en la novela se recogen las tradiciones folklóricas y la poesía popular, pero en ningún caso se valoran positivamente la superstición o la magia, que forman parte de la lógica irracional que debe quedar fuera del nuevo consenso. Con ello se hace evidente que el arte popular asimilable por el conjunto de la sociedad es aquel que establece una relación necesaria entre el fondo y la forma, pero en ningún caso las creencias mágicas,

18 Doris Sommer ha señalado que "en la novela persiste una tensión estilística entre el carácter narrativo 'clásico’ y los coloquialismos potencialmente desconcertadores contenidos (en ambos sentidos) en el estilo controlado. [...] Pero las extravagancias son puramente léxicas, nunca gramaticales, nunca alteran la estructura del lenguaje" (2004: 357). En el mismo orden de ideas, la profesora de Harvard señala: "Gallegos está sin duda reinscribiendo el exceso y la diseminación, poniendo el dedo en la llaga del lenguaje que sigue desbordando el significado cada vez que se intenta contener su flujo. Cuando escenifica la obligación y la sutura, se escapan los caprichos del habla popular, la gente y el ganado errantes. Pero a pesar de todo él continúa actuando, imponiendo su control con algunos resultados quizás temporales" (362). 
ya que éstas, con su dimensión excesiva y rizomática, podrían quebrar las bases mismas de la racionalidad que debía fundar el orden social. Como ha indicado Doris Sommer, Doña Bárbara puede ser leída como una alegoría moralizadora, es decir, como un episodio en que "la santa luz de la Razón moderna destierra la oscuridad arcaica de la Bárbara magia negra, la fuente de poder antagonista" (2004: 353). Por eso la transformación de "la bruja del Arauca" es evidente desde el momento en que comienza a preferir las artes femeninas al uso de la magia:

Por un momento se le ocurrió valerse de sus "poderes" de hechicería, conjurar los espíritus maléficos obedientes a la voluntad del dañero, pedirle al "Socio" que le trajera al hombre esquivo; pero inmediatamente rechazó la idea con una repugnancia inexplicable. La mujer que había aparecido en ella la mañana de Mata Oscura quería obtenerlo todo por artes de mujer (298).

En ese sentido, observamos que no todas las formas culturales del pueblo son aceptadas por la voz narrativa, sino solo las que pueden ser controladas por la inteligencia letrada, o aquellas que proceden del folklore y que plantean una relación inequívoca entre el significante y el significado, entre el medio y el hombre. Esta actitud y otras que hemos señalado muestran que Rómulo Gallegos fue sensible al discurso de la autenticidad que en los años veinte y treinta del siglo pasado defendieron también otros intelectuales hispanoamericanos de primer orden como Pedro Henríquez Ureña, Alfonso Reyes o Mariano Picón Salas. De acuerdo con este discurso, las élites debían reconocer al pueblo y establecer una unión armónica con él, sin embargo, como ha indicado Julie Skurski, en la práctica esto supuso un interés exclusivo por las energías populares que eran asimilables al proyecto de las élites (1994: 605).

Es patente entonces que, en muchos aspectos diferentes, Doña Bárbara propone una síntesis entre el individuo y su mundo, entre la forma y el contenido, entre las élites letradas y el pueblo dócil y trabajador. La novela promueve así un consenso ético tanto en el plano político como en el estético y concibe la noción de síntesis dialéctica como el único camino para alcanzar la modernidad y, a través de ella, la universalidad. 
Sin embargo, este orden político y estético ideal sólo se puede definir y, en última instancia, realizar, a través de la exclusión de los excesos y del otro-radical. La presencia del suplemento resulta así imprescindible para la definición del orden político liberal y mestizo que promueve la novela, y también es necesario para la conformación de un orden lingüístico y estético sólido, en que las partes remitan al todo y en que no haya elementos sobrenumerarios capaces de destruir la propiedad de la significación y la noción de cultura. En el plano político, pero también en el estético y en el lingüístico, Doña Bárbara proyecta un orden armónico y homogéneo, pero este orden se alcanza sólo a partir de la exclusión de lo que está de más. Es a partir de esta sustracción, presente en los diferentes planos de la novela, que se establece el consenso político y estético que esta defiende.

BibLIOGRAFíA

AlONSO, CARLOS J. "Otra sería mi historia: Allegorical Exhaustion in Doña Bárbara”. Modern Languaje Notes 104.2 (1989): 418-438.

Castro-Urioste, José. "La imagen de nación en Doña Bárbara". Revista de Crítica Literaria Latinoamericana xx. 39 (1994/1): 127-139.

Dessau, ADALBERT. "Realidad social, dimensiones históricas y método artístico en Doña Bárbara de Rómulo Gallegos”. Luis Enrique Osorio (ed.). Doña Bárbara ante la crítica. Caracas: Monte Ávila Editores, 1991. 129-144.

Galuegos, Rómulo. Doña Bárbara. Domingo Miliani editor. Madrid: Cátedra, 2015.

"El factor educación". Obras selectas. Caracas/Madrid: Ediciones Edime/Editorial Mediterráneo, 1977.

. "Necesidad de valores culturales". Obras selectas. Caracas/Madrid: Ediciones Edime/Editorial Mediterráneo, 1977.

GonzáLEz ECheverRíA, ROBERTO. "Doña Bárbara escribe la ley del llano". La voz de los maestros. Madrid: Verbum, 2001. 71-109. 
LASARTE, JAVIER. "A 80 años de Doña Bárbara: hacer cosas con el pueblo y la nación". Akademos 13. 1-2 (2011): 35-56.

MOREIRAS, AlBERTO. Línea de sombra. El no-sujeto de lo político. Santiago de Chile: Palinodia, 2006.

Mouffe, Chantal. En torno a lo político. Buenos Aires: FCE, 2011.

Ranciere, JaCQues. "Diez tesis sobre la política". Política, policía, democracia. Santiago de Chile: Lom, 2007.

Rodríguez MONEGal, Emir. "Doña Bárbara: texto y contextos". Luis Enrique Osorio (ed.). Doña Bárbara ante la crítica. Caracas: Monte Ávila Editores, 1991. 119-128.

SkURSKI, Julie. "The Ambiguities of Authenticity in Latin America: Doña Bárbara and the Construction of National Identity". Poetics Today 15.4 (1994): 605-642. Loci of Enunciation and Imaginary Constructions: The Case of (Latin) America, I.

SOMmer, Doris. Ficciones fundacionales. México: FCE, 2004. 